\title{
A NETWORK ANALYSIS OF THE ASIA-PACIFIC AND OTHER DEVELOPED STOCK MARKETS: PRE AND POST GLOBAL FINANCIAL CRISIS
}

\section{KOUSIK GUHATHAKURTA', SHARAD NATH BHATTACHARYA2*, MOUSUMI BHATTACHARYA 2}

1. Indian Institute of Management Indore, Finance and Accounting Area, India

2. Indian Institute of Management Shillong, Finance and Control Area, India

* Corresponding Author: Sharad Nath Bhattacharya, Indian Institute of Management Shillong, Meghalaya, East Khasi Hills, 793014, India. $\quad$ ? +91 (364) 2308000 \$ sharadbhattacharya@gmail.com

\begin{abstract}
The paper examines the volatility spillover and connectedness between Asia-Pacific, US, UK, and eurozone stock markets. A spillover index is built using forecast error variance decomposition in a vector autoregression framework and the spillover index is used to build network diagrams. It shows evidence of how the increase in risk transfer (volatility spillover) between the markets led to the global financial crisis and of the higher level of connectedness since. The time variations in spillover are aligned with recognizable international events. Network diagrams show the direction and strength of the connectedness. The Chinese market appears to be the most insulated, while the South Korean, Hong Kong, and Singapore stock markets dominate in terms of risk transfer. The US, UK, EU, Singapore and Hong Kong are the top five volatility spillover recipient markets, both during pre and post global financial crisis periods. We find the market size to be irrelevant in the determination of the level of connectedness, whereas the role of geographical proximity cannot be ruled out. The findings are relevant to multinational investment strategies and in understanding the relative risk of investment in the Asia-Pacific region.
\end{abstract}

Keywords: Connectedness; European Debt Crisis; Global Financial Crisis; Network Diagrams Volatility Spillover Index.

\section{Introduction}

One of the questions at the centre of contemporary financial research is how markets influence each other. Connectedness in terms of risk and return has been a popular research topic, since news that affects one country's stock prices can potentially change the fundamentals of another country, causing fluctuations in its stock prices. Consequently, intermarket connectedness not only affects the decisions of individual agents (e.g., portfolio management) but also contributes to systemic risk. The impact of market connectedness was evident during the 2008 global financial crisis and the European debt crisis (EDC). Under the wake-up call hypothesis, a financial shock or crisis in one financial market acts as a wake-up call to investors in another market, and these investors then reassess and acquire information about local market fundamentals (Forbes, 2012). Such reappraisals of risk spread the crisis from one market to another. Understanding the directional connectedness and network strength of financial markets influences the portfolio management decisions of international funds. The value of such knowledge is becoming increasingly critical in portfolio management, since there is increasing regulatory and fundamental convergence across financial markets, driving out the diversification potential for investors (Forbes \& Rigobon, 2002; Markwat et al., 2009; Alovi et al., 2011). Estimation of the strength of the network of markets helps policymakers understand the spillover of a crisis in the event of a trigger in one country. A comprehensive network-based study of multiple markets can discern the risk involved in investing in that country in times of impending crisis. 
The present study uses a generalized vector autoregression (VAR) methodology and the variance decomposition matrix of Diebold and Yilmaz $(2012,2014,2016)$ to understand the directional connectedness of markets. Diebold and Yilmaz's methodology measures the volatility spillover between the countries, and it does not distinguish between contagion and interdependence. This feature is useful when a policymaker wants to know what country (or group of countries) is more vulnerable to the volatility spillover from another country. We show network diagrams indicating the relative strength and direction of spillover between countries. The findings are relevant to multinational investment strategies and help in understanding the relative risk of investment in strategically important groups of markets.

Since most of the decision areas affected by market connectedness are related to risk management, this study looks at the network from a volatility spillover or risk transfer perspective. It examines the network dynamics of a group of stock markets from the Asia-Pacific region, along with the US, UK, and eurozone markets, during the period from 2000 to 2019 . We examine the degree of volatility spillover between the US, UK, EU, and Asia-Pacific markets and how likely the Asia-Pacific markets are to be affected by an emerging crisis in the developed markets. The 2008 global financial crisis is in the middle of the period of study, and we assess how network strength changed, leading to the crisis, and its status after the crisis. We also examine the time-varying volatility spillover levels during the entire period covering the European debt crisis. Related questions undertaken in our study concerned the spillover bursts during crisis periods, the importance of market size in volatility spillover across markets and whether geographical proximity plays a role in risk transfer (Rejeb \& Boughrara, 2015). The importance of the present study lies in unearthing the relative risk of investment in Asia-Pacific stock markets and identifying the Asia-Pacific markets that have higher/lower directional spillover and higher/lower risk in case of an impending crisis.

The Asia-Pacific region represents a group of emerging and developed financial markets with established financial instruments, regulatory and legal frameworks, market infrastructure, and a critical mass of market participants. In the Asia-Pacific region, most of the stock markets are in open economies (e.g., Hong Kong, Taiwan, Shanghai, and Korea), which rely very much on external trade, their largest markets being the United States, the United Kingdom, and the European Union (EU). It is possible that their individual comovement with the US and EU markets causes connectedness between these Asia-Pacific stock markets, US and EU markets. The study would thus be incomplete if EU and US market data were not a part of the sample.

The remainder of the paper is organized as follows. Section 2 briefly reviews the literature. Section 3 describes the data, followed by an elaboration of the methodology. Section 4 presents data analysis, results, and findings. Section 5 concludes the paper.

\section{Literature Review}

The terms connectedness, contagion, and spillover are widely used in financial market research. While Engle et al. (1990) focused on causality in the variance between markets for volatility spillover, Forbes and Rigobon (2002) used contagion to understand the cross-market linkages after a shock. While all of the terms indicate the transmission of shocks unexplained by fundamentals or comovement, Billio and Pelizzon (2003) provide a concise discussion of the terms, their measurements, along with restrictions on their definitions. Research on volatility spillover possibly originated in response to the October 1987 crisis in the United States that spread across markets. Researchers have provided evidence that the volatility of one country leads to fluctuations in prices in other countries. The source and destination can be developed or emerging nations.

Volatility spillover is explained by information transmission theory (Ross, 1989), which in turn helps us in deciphering how price and volatility affect information flow and the efficiency of the stock markets. While explaining similar time-varying volatility across international stock markets, Engle and Susmel (1993) argued for the presence of regional factors with time-varying variance. Longin and 
Solnik (1995) noted that the conditional correlation between the monthly returns of international stock markets is not constant, it had increased between 1960 and 1990, and it is higher when the stock markets experience high volatility. Other inspiring works on contagion and volatility spillover include those of Kearney (2000), Ling and McAleer (2003), Cappiello et al. (2006), Diebold and Yilmaz $(2009,2012,2014,2016)$, Silvennoinen and Terasvirta (2009), Conrad and Karanasos (2010), and Bauwens et al. (2013) and references therein. Anastasopoulos (2018) showed that both the Greek debt crisis and the effects of the yuan devaluation produced contagion effects.

The preferred methodology of early researchers involved variations of the generalized autoregressive conditional heteroskedasticity (GARCH) model. Alper and Yilmaz (2004) evidenced volatility spillover from countries with active financial centres to the Istanbul Stock Exchange during the Asian financial crisis. Supporting the use of the MGARCH model for spillover studies, Bauwens ef al. (2006) noted the model's efficiency in capturing transmission through a conditional variance or conditional covariance, while Allen et al. (2013) calculated conditional correlations and spillover using multivariate GARCH to capture the spillover effects from China to different markets in the Pacific Basin area during the financial crisis from 2007 to 2008. Using the asymmetric multivariate GARCH model proposed by Engle and Kroner (1995) and extended by Kroner and Ng (1998), Li and Giles (2015) evidenced unidirectional shock and volatility spillover from the US market to China, India, Japan, Malaysia, Indonesia, the Philippines, and Thailand in general, but a more robust, bidirectional relationship during the Asian financial crisis. Hemche et al. (2016) used a DCCMGARCH model to show that the correlation between the US and other developed and emerging markets increased during the subprime crisis and the European sovereign debt crisis in 2009-10.

In parallel to studies using the GARCH methodology to study connectedness, Gallo \& Otranto, (2008) used regime-switching volatility, spillover models. Dungey and Gadjurel (2014) relied on a latent factor model to detect and measure the extent of contagion effects from the United States to other developed and emerging nations that explains a large portion of the variance in both these markets. Nomikos and Salvador (2014) studied volatility transmission patterns by using a Markov bivariate BEKK model, while Otranto (2015) observed spillover between the United States, Japan, the eurozone, and Hong Kong using a multiplicative error model that decomposes part of the mean volatility into a spillover-measuring component that can be appropriately studied and interpreted. Using variance decompositions from VAR, Guimarães-Filho, and Hong (2016) examined the time-varying characteristics of their measure and the connectedness between China's equity markets and other major equity markets. They found significant spillover from China to both developed and emerging markets. However, BenSaïda et al. (2018) noted that the abovementioned studies focus on two countries at a time (bivariate) and hence lack multi-country connectedness dynamics. The authors used a Markov switching VAR model to show that spillover increases during crises.

The majority of prior research in spillover and connectedness has applied multivariate GARCH, regime-switching, and stochastic volatility models. However, the finance community has noted a departure from the inclination to use these methods, with Diebold and Yilmaz (2009) providing an index measure of returns and volatility spillover based on forecast error variance decomposition within a VAR framework. Using this methodology, Diebold and Yilmaz (2011) evidenced widely varied levels of spillover in both risk and returns between Argentina, Brazil, Chile, Mexico, and the United States, while Yilmaz (2010) evidenced return and volatility spillover among major Asian countries. Diebold and Yilmaz (2012) upgraded their 2009 method, making the error variance decomposition order invariant and using this newer model to provide evidence of limited crossmarket spillover between US stocks, bonds, foreign exchanges, and commodity markets until the subprime crisis, and a significant increase in volatility after the collapse of Lehman Brothers. Tsai (2014) used Diebold and Yilmaz's (2012) approach to show that information transmission between five developed stock markets - the United States, the United Kingdom, Japan, France, and Germany - increased significantly after 1998, with the US stock market showing positive net spillover before 1997, during the dot-com bubble, and during the subprime crisis. Building connectedness 
measures from this variance decomposition, Diebold and Yilmaz (2016) evidenced unidirectional spillover from the United States to Europe from 2007 to 2008. However, they showed that this connectedness became bidirectional starting in late 2008. The authors also reported that, as the condition of financial institutions in Europe dwindled, spillover from European to US financial institutions increased in June 2011 . Demirer et al. (2018) reported that banking stock connectedness increases during crises, with cross-country linkages providing more fluctuations than within-country bank linkages. Caloia et al. (2018) built on Diebold and Yilmaz's (2012) model. They used a multivariate extension of the heterogeneous autoregressive model to show asymmetric risk transmission between Germany, France, the Netherlands, Italy, and Spain. Baruník et al. (2016) modified the Diebold-Yilmaz (2012) model to consider and differentiate between volatilities from positive and negative changes in prices. They then reported that connectedness across sectors is asymmetric and of different strengths. Xu et al. (2018) used a multiplicative error model based on that of Diebold and Yilmaz (2009) to report high interdependency across equity markets in terms of volatility and illiquidity, with increased interdependency increased during the global financial crisis.

Complex network diagrams are used to characterize the structure of the linkages in a financial system. Nobi et al. (2014) showed structural changes in a network diagram of the correlations between stock market prices and attributed them to the global crisis, while Zhao et al. (2016) provided for the dynamic evolution of stock markets in crises. Wang et al. (2018) proposed a correlation-based network to analyse the correlation structure and evolution of world stock markets. They argued that the connectedness between two stock markets is significantly affected by other markets and that, during the subprime crisis, the stock markets were highly correlated with the quick transmission of information. Bhattacharjee et al. (2019), using network theory, explored the connectedness of between 14 Asian capital markets and showed the influence of the 2008 financial crisis on the connectivity and clustering patterns in the network of Asian indexes.

In the context of the Asia-Pacific markets, empirical work on the relationship between stock markets have provided varied evidence. Asia Pacific region has some of the most important equity markets in the world, both in terms of market capitalization and traded volume (Ferris et al. 2007). However, the role of the US equity market as a source of volatility Spillover or a volatility contributor to Asia Pacific markets has been demonstrated in Liu and Pan (1997), Alaganar and Bhar (2002), Cheng and Glascock (2006) and Kolluri et al. (2014). Johnson and Soenen (2002) advocate a substantial degree of interaction between the Japanese stock market and those in New Zealand, Hong Kong, China and Australia. They concluded that rising export and FDI flow from Japan are the key contributors to this relation. Alaganar and Bhar (2002) reveal that fluctuations in US equities have a significant effect on both the return and the volatility of the Australian equity market. There have been varying reports of the integration of the Chinese stock market with other markets. Johansson and Ljungwall (2009) illustrate that the Chinese stock market volatility has had a short-term effect due to Spillover from Hong Kong and Taiwan, while Mitra and lyer (2016) demonstrate that the Chinese stock market is the least integrated share market in the Asia Pacific. Abidin et al. (2014) advocated the connectedness between the Chinese, Australian, Hong Kong and New Zealand stock markets, while stressing on the emerging connectedness between Australia and the Chinese equity markets. Spillover effects from China on different Asia Pacific markets are recorded by Allen et al. (2013) and Ahmed and Huo (2019), while Guimarães-Filho and Hong (2016) note that China has increasingly become a net "giver" of spillover volatility in the Asia Pacific region. Li and Giles (2015) and Bissoondoyal-Bheenick et al. (2018) have shown a one-way volatility spillover from the US market to China. Allen et al. (2017) studied the volatility spillover between Australia, China, Japan, Korea and the United States during 2004-2014. They noted that China (includes Hong Kong) and US markets have the greatest influence on the Australian market. Bissoondoyal-Bheenick et al. (2018) report an insignificant volatility spillover in selected sectors from the Australian to the Chinese stock markets. This study reassesses the importance of the Chinese stock market in terms of its connectedness with other markets. 
The literature review summarizes and points towards changes in the magnitude and direction of the connectedness across markets. We augment the literature while building complex network diagrams within a quantifiable framework based on the work of Diebold and Yilmaz (2012) to show how connectedness changed as the markets approached the subprime crisis and to compare their connectedness during the pre- and post-subprime crisis periods. Given China's different market microstructure, we explore how China differs from its neighbours.

\section{Data and Methodology}

We consider the daily data from April 2000 to April 2019 on 11 stock market indexes from the AsiaPacific region: All Ordinaries index (AORD) in Australia, Hang Seng index (HSI) in Hong Kong, Nikkei index (NIKKEI) in Japan, Straits Times Index (STI) in Singapore, SSE Composite Index (SSE) in China, NIFTY 50 index (NIFTY) in India, Jakarta Stock Exchange Composite index (JKSE) in Indonesia, Korea Composite index (KOSPI) in South Korea, Bursa Malaysia KLCI Index (KLSE) in Malaysia, Philippine Stock Exchange index (PSEI) in the Philippines and Taiwan Weighted index (TWII) in Taiwan. The data are obtained from the Thomson Reuters database. Lehman Brothers filed for bankruptcy on 15 September 2007. We consider this event like the announcement of the subprime crisis, and the date is considered for the sample split. Thus, the period from 03 April 2000 to 15 September 2007 is considered as pre subprime crisis period leading to the subprime crisis while 16 September 2007 to 03 April 2019 is considered as post subprime crisis period. Many countries with an open economy considered above (e.g., Hong Kong, Taiwan, Shanghai, and Korea) rely on external trade, especially with the United States and the eurozone. Their comovement can cause the spillover between these Asia-Pacific stock markets and US and EU markets. To gain a comprehensive and unified idea of the connectedness between these markets, we include the following stock market indexes in the study: the Dow Jones Industrial Average (DJI) for the United States, the Financial Times Stock Exchange (FTSE) 100 for the United Kingdom, and the EURO STOXX 50 Index for the eurozone. The returns from these markets are the logarithmic differences of the indexes. Following empirical literature (Diebold \& Yilmaz, 2012, and references therein), the daily variance for market $i$ on day $t$ is estimated as $\tilde{\sigma}_{\mathrm{it}}^{2}=0.361\left[\ln \left(\mathrm{M}_{\mathrm{it}}^{\max }\right)-\ln \left(\mathrm{M}_{\mathrm{it}}^{\min }\right)\right]^{2}$, where $\mathrm{M}_{\mathrm{it}}^{\max }$ is the maximum (high) price in the market $i$ on day $t$ and $M_{i t}^{\min }$ is the daily minimum (low) price. The estimate of the annualized daily volatility is $\hat{\sigma}_{\mathrm{it}}=100 \sqrt{365 \times \tilde{\sigma}_{\mathrm{it}}^{2}}$.

We develop the spillover index, as suggested by Diebold and Yilmaz (2014). This index is an improvement over their 2009 spillover index since it not only avoids the sensitivity of the forecast error variance decomposition on the ordering of the variables in the VAR framework but also considers correlated shocks. For each Asia-Pacific stock market $i$, we consider the forecast error variances to be from two sources-the fraction of $\mathrm{H}$-step-ahead error variance in forecasting $\mathrm{x}_{i}$ that is due to shocks to $x_{i}$, for $i=1,2, \ldots, N$, and spillover as a fraction of the $\mathrm{H}$-step-ahead error variance in forecasting $x_{i}$ that is due to shocks to $x_{j}$, for $i, j=1,2, \ldots, N$, where $\forall j \neq i$. The spillover index is obtained as the sum of all the non-diagonal elements in the forecast error variance matrix.

We model Asia-Pacific stock market returns (or volatility) as a covariance stationary N-variable $\operatorname{VAR}(\mathrm{p})$ framework represented by $\mathrm{x}_{\mathrm{t}}=\sum_{\mathrm{i}=1}^{\mathrm{p}} \Phi_{\mathrm{i}} \mathrm{x}_{\mathrm{t}-1}+\varepsilon_{\mathrm{t}}$ where $\varepsilon_{\mathrm{t}}$ is a vector of independently and identically distributed disturbances with zero mean and covariance matrix $\sum$. As a tool for variance decomposition analysis, we represent the above VAR (p) framework in the moving average (MA) process as $x_{t}=\sum_{i=0}^{\infty} \Theta_{i} \varepsilon_{t-1}$, where $\Theta_{i}$ is the $N \times N$ matrix of $M A$ coefficients that conforms to the following recursion: $\Theta_{\mathrm{i}}=\Phi_{1} \Theta_{\mathrm{i}-1}+\Phi_{2} \Theta_{\mathrm{i}-2}+\ldots+\Phi_{\mathrm{p}} \Theta_{\mathrm{i}-\mathrm{p}}$, with $\Theta_{0}$ an $\mathrm{N} \times \mathrm{N}$ identity matrix and $\Theta_{\mathrm{i}}=0$ for $\forall \mathrm{i}<0$. 
We next consider the variance decomposition, which allows us to deconstruct the forecast error variance of each variable into parts that are attributable to the various system shocks. Specifically, we look for the fraction of the $\mathrm{H}$-step-ahead error variance in forecasting $x_{i}$ that is due to shocks to $x_{j}$, $\forall \mathrm{j} \neq \mathrm{i}$. We use directional spillover in the generalized VAR framework of Koop et al. (1996) and Pesaran and Shin (1998) to obtain H-step-ahead forecast error variance decomposition as $\xi_{i j}^{g}(H)=\frac{\sigma_{j j}^{-1} \sum_{h=0}^{H-1}\left(e_{i}^{\prime} \Theta_{h} \sum e_{j}\right)^{2}}{\sum_{h=0}^{H-1}\left(e_{i}^{\prime} \Theta_{h} \sum \Theta_{h}^{\prime} e_{i}\right)}$, where the variance matrix for the error vector $\varepsilon$ is denoted by $\Sigma$; $e_{i}$ is the selection vector, with one as the ith element, and zero otherwise; $\sigma_{\mathrm{jj}}$ is the standard deviation of the error term for the $j$ th equation; and $\sum_{j=1}^{N} \xi_{i j}^{g}(H) \neq 1$. We then normalize each entry of the variance decomposition matrix by the row sum, as $\tilde{\xi}_{\mathrm{ij}}^{\mathrm{g}}(\mathrm{H})=\frac{\xi_{\mathrm{ij}}^{\mathrm{g}}(\mathrm{H})}{\sum_{\mathrm{j}=1}^{\mathrm{N}} \xi_{\mathrm{ij}}^{\mathrm{g}}(\mathrm{H})}$, and we maintain $\sum_{\mathrm{j}=1}^{\mathrm{N}} \tilde{\xi}_{\mathrm{ij}}^{\mathrm{g}}(\mathrm{H})=1$ and $\sum_{\mathrm{i}, \mathrm{j}=1}^{\mathrm{N}} \tilde{\xi}_{\mathrm{ij}}^{\mathrm{g}}(\mathrm{H})=\mathrm{N}$.

From the above variance decomposition, the total cross variation or total spillover index is calculated as $I^{\mathrm{g}}(\mathrm{H})=\frac{\sum_{\substack{\mathrm{i}, \mathrm{j}=1 \\ i \neq 1}}^{\mathrm{N}} \tilde{\xi}_{\mathrm{ij}}^{\mathrm{g}}(\mathrm{H})}{\sum_{\mathrm{i}, \mathrm{j}=1}^{\mathrm{N}} \tilde{\xi}_{\mathrm{ij}}^{\mathrm{g}}(\mathrm{H})} \times 100$. This total spillover index measures the contribution of the spillover of volatility shocks across Asia-Pacific stock markets, including the US and EU area, to the total forecast error variance.

The directional spillover received by market $i$ from all the other markets $j$, assuming the normalized elements of the generalized variance decomposition matrix, is $I_{\mathrm{i} \leftarrow \bullet}^{\mathrm{g}}(\mathrm{H})=\frac{\sum_{\substack{\mathrm{j}=1 \\ j \neq i}}^{\mathrm{N}} \tilde{\xi}_{\mathrm{j} j}^{\mathrm{j}}(\mathrm{H})}{\sum_{\mathrm{i}, \mathrm{j}=1}^{\mathrm{N}} \tilde{\xi}_{\mathrm{jij}}^{\mathrm{g}}(\mathrm{H})} \times 100$. The directional volatility spillover transmitted from market $i$ to all the other markets $j$ is $\mathrm{I}_{\bullet \leftarrow \mathrm{i}}^{\mathrm{g}}(\mathrm{H})=\frac{\sum_{\mathrm{j}=1}^{\mathrm{N}} \tilde{\xi}_{\mathrm{ji}}^{\mathrm{g}}(\mathrm{H})}{\sum_{\mathrm{i}, \mathrm{j}=1}^{\mathrm{N}} \tilde{\xi}_{\mathrm{ji}}^{\mathrm{g}}(\mathrm{H})} \times 100$. The difference between the total volatility shocks to and from all the other markets is the net volatility spillover, denoted by $I_{i}^{g}(H)=I_{\leftarrow i}^{g}(H)-I_{i \leftarrow}^{g}(H)$. Net volatility spillover helps us understand how much a stock market contributes to the volatility of other selected markets. The net pairwise volatility spillover between stock markets is, therefore $\xi_{\mathrm{ij}}^{\mathrm{g}}(\mathrm{H})=\left(\frac{\tilde{\xi}_{\mathrm{ji}}^{\mathrm{g}}(\mathrm{H})-\tilde{\xi}_{\mathrm{ij}}^{\mathrm{g}}(\mathrm{H})}{\mathrm{N}}\right) \times 100$.

We develop a network diagram based on the spillover index to explore the connectedness between the chosen countries. Connectedness is central to all risk management practices worldwide and can help us in understanding how changes in the systemic risk of a single country multiply and affect global markets. Traditional methods used in connectivity studies employ correlation-based measures; these measures only pairwise association and are skewed toward linearity and Gaussian assumptions, restricting their acceptance in financial market contexts. The marginal expected shortfall method (Acharya et al., 2010), the conditional value at risk (CoVaR) method (Adrian \& Brunnermeier, 2011), and the equicorrelation method (Engle \& Kelly, 2012) have generated much interest, but, as Diebold and Yilmaz (2014) pointed out, these methods measure different things. There exists no unified framework of global or regional connectedness. Here we use the connectedness measurement proposed by Diebold and Yilmaz (2014), which is closely related both to modern 
network theory and defines a network by variance decomposition. Diebold and Yilmaz argued that these variance decomposition networks are more sophisticated than traditional networks and consider total directional connectedness. The total spillover $\mathrm{I}^{\mathrm{g}}(\mathrm{H})$ is the total connectedness or system-wide connectedness. In understanding connectedness and its better representation, we build network diagrams using system-wide connectedness and three previously calculated measures:

total directional connectedness from all other firms $j$ to firm $i: I_{i \leftarrow \bullet}^{g}(H)=\frac{\sum_{\substack{j=1 \\ j \neq i}}^{N} \tilde{\xi}_{i j}^{g}(H)}{\sum_{i, j=1}^{N} \tilde{\xi}_{i j}^{g}(H)} \times 100$
total directional connectedness from firm $i$ to all other firms $j: I_{\bullet \leftarrow i}^{g}(H)=\frac{\sum_{j=1}^{N} \tilde{\xi}_{j i}^{g}(H)}{\sum_{i, j=1}^{N} \tilde{\xi}_{j i}^{g}(H)} \times 100$

net directional connectedness from market $i$ to all other markets $j: I_{\mathrm{i}}^{\mathrm{g}}(\mathrm{H})$

Diebold and Yilmaz (2009) noted that the connectedness matrix converges quickly to a stable value when $\mathrm{H}$ increases, but it changes when $\mathrm{H}$ is tiny, especially if it is smaller than the order of the VAR.

Several events took place during our sample period that may have impacted the spillover. The spillover table possibly misses the time-varying nature of spillover and the impact of these events as it provides a useful average behaviour of spillover. Hence, we estimate the time-varying spillover of volatility over the full sample period using 150 days rolling data. The time-varying spillover plot is presented to capture the variation of volatility transmission over time, and it is connected with the economic events. Finally, we supplement the network diagrams of pre and post subprime crisis periods with the network diagrams for the periods of spillover bursts.

\section{Data Analysis and Findings}

The initial description (see Table 1.1) of the volatilities of the markets indicates that all the market volatilities are leptokurtic, and positively skewed in both the pre-and post-crisis periods. While all the countries showed changes in skewness and kurtosis between the pre- and post-crisis periods, the difference is minimal in the case of China. Table 1.2 shows that the mean returns are positive for all the chosen market indexes, except for the eurozone, Japan, and Taiwan. All the return series deviate from the Gaussian distribution, as evidenced by their skewness and kurtosis. The results of the augmented Dickey-Fuller test (ADF) show that the returns and volatilities of all the markets are stationary at the $1 \%$ level of significance.

\subsection{Unconditional Patterns: The Full-Sample Volatility Spillover Table}

The total spillover index values provided in Table 2 captures the spillover dynamics of the Asia-Pacific region. All the outcomes are based on second-order VAR with 10-step-ahead forecasts. We estimated initial VAR models with high order lags of the variables and finally selected the VAR (lag 2) model based on minimum information criteria as indicated by AIC. 
Table 1.1: Descriptive Statistics: Daily Volatility

\begin{tabular}{|c|c|c|c|c|c|c|c|c|c|}
\hline Markets & Period & Mean & Median & Maximum & Minimum & Std. Dev. & Skewness & Kurtosis & ADF \\
\hline \multirow{3}{*}{$\begin{array}{l}\text { Australia } \\
\text { (AORD) }\end{array}$} & Pre & 0.000039 & 0.00002 & 0.00183 & 0.000001 & 0.00008 & 11.73 & 206.63 & $-12.95^{*}$ \\
\hline & Post & 0.000046 & 0.00003 & 0.00085 & 0 & 0.00006 & 5.92 & 59.4 & $-10.26^{*}$ \\
\hline & Combined & 0.00005 & 0.00003 & 0.00236 & 0 & 0.0001 & 9.99 & 162.73 & $-10.66^{*}$ \\
\hline \multirow{3}{*}{$\begin{array}{l}\text { USA } \\
\text { (DJI) }\end{array}$} & Pre & 0.000091 & 0.00005 & 0.00262 & 0.000002 & 0.00014 & 6.88 & 95.55 & $-6.43^{*}$ \\
\hline & Post & 0.000063 & 0.00003 & 0.00343 & 0.000002 & 0.00014 & 13.54 & 277.83 & $-10.22^{*}$ \\
\hline & Combined & 0.0001 & 0.00004 & 0.004 & 0.000002 & 0.00021 & 8.99 & 118.79 & $-7.45^{*}$ \\
\hline \multirow{3}{*}{$\begin{array}{l}\text { Eurozone } \\
\text { (EURO) }\end{array}$} & Pre & 0.000157 & 0.00007 & 0.00327 & 0.000003 & 0.00026 & 4.83 & 37.18 & $-5.99 *$ \\
\hline & Post & 0.000133 & 0.00007 & 0.00377 & 0.000001 & 0.00022 & 7.68 & 93.38 & $-10.42^{*}$ \\
\hline & Combined & 0.00016 & 0.00008 & 0.00377 & 0.000001 & 0.00027 & 5.37 & 45.34 & $-9.43^{*}$ \\
\hline \multirow{3}{*}{$\begin{array}{l}\text { UK } \\
\text { (FTSE100) }\end{array}$} & Pre & 0.000107 & 0.00005 & 0.00213 & 0.000002 & 0.00018 & 5.36 & 45.22 & $-8.25^{*}$ \\
\hline & Post & 0.000082 & 0.00004 & 0.00297 & 0.000002 & 0.00015 & 9.77 & 158.35 & $-11.5^{*}$ \\
\hline & Combined & 0.00011 & 0.00005 & 0.00339 & 0.000002 & 0.00021 & 7.26 & 79.44 & $-8.20 *$ \\
\hline \multirow{3}{*}{$\begin{array}{l}\text { Hong } \\
\text { Kong } \\
\text { (HSI) }\end{array}$} & Pre & 0.000093 & 0.00006 & 0.00153 & 0 & 0.00013 & 4.76 & 38.49 & $-9.73^{*}$ \\
\hline & Post & 0.00007 & 0.00004 & 0.00164 & 0.000004 & 0.00011 & 7.59 & 85.05 & $-13.35^{*}$ \\
\hline & Combined & 0.0001 & 0.00005 & 0.0055 & 0 & 0.00019 & 12.2 & 260.65 & $-6.92 *$ \\
\hline \multirow{3}{*}{$\begin{array}{l}\text { Indonesia } \\
\text { (JKSE) }\end{array}$} & Pre & 0.000114 & 0.00006 & 0.00286 & 0 & 0.00018 & 6.68 & 71.12 & $-12.32^{*}$ \\
\hline & Post & 0.000075 & 0.00003 & 0.00327 & 0.000002 & 0.00016 & 10.26 & 164.6 & $-11.52^{*}$ \\
\hline & Combined & 0.00011 & 0.00005 & 0.00583 & 0 & 0.00022 & 10.8 & 204.99 & $-11.56 *$ \\
\hline \multirow{3}{*}{$\begin{array}{l}\text { Malaysia } \\
\text { (KLSE) }\end{array}$} & Pre & 0.000056 & 0.00003 & 0.00182 & 0 & 0.0001 & 7.71 & 93.34 & $-15.30^{*}$ \\
\hline & Post & 0.000021 & 0.00001 & 0.00064 & 0.000001 & 0.00004 & 8.72 & 110.37 & $-10.71 *$ \\
\hline & Combined & 0.00004 & 0.00002 & 0.00182 & 0 & 0.00008 & 8.66 & 124.26 & $-11.45^{*}$ \\
\hline \multirow{3}{*}{$\begin{array}{l}\text { South } \\
\text { Korea } \\
\text { (KOSPI) }\end{array}$} & Pre & 0.000171 & 0.0001 & 0.00275 & 0.000007 & 0.00023 & 4.06 & 27.99 & $-8.30 *$ \\
\hline & Post & 0.000053 & 0.00003 & 0.00202 & 0 & 0.00011 & 9.42 & 135.62 & $-14.74^{*}$ \\
\hline & Combined & 0.00013 & 0.00006 & 0.00906 & 0 & 0.00028 & 15.21 & 411.41 & $-13.61^{*}$ \\
\hline \multirow{3}{*}{$\begin{array}{l}\text { India } \\
\text { (NIFTY) }\end{array}$} & Pre & 0.000243 & 0.00011 & 0.01495 & 0.00001 & 0.00058 & 14.97 & 325.61 & $-18.82^{*}$ \\
\hline & Post & 0.000075 & 0.00004 & 0.00125 & 0 & 0.00009 & 4.89 & 46.35 & $-13.56^{*}$ \\
\hline & Combined & 0.00019 & 0.00008 & 0.01495 & 0 & 0.0005 & 16.44 & 397.57 & $-18.53^{*}$ \\
\hline \multirow{3}{*}{$\begin{array}{l}\text { Japan } \\
\text { (NIKKEI) }\end{array}$} & Pre & 0.000106 & 0.00007 & 0.00288 & 0.000003 & 0.00014 & 8.93 & 143.33 & $-11.17^{*}$ \\
\hline & Post & 0.000084 & 0.00004 & 0.00684 & 0.000001 & 0.00027 & 16.68 & 362.21 & $-19.71^{*}$ \\
\hline & Combined & 0.00011 & 0.00006 & 0.00684 & 0.000001 & 0.00026 & 13.67 & 267.44 & $-12.64^{*}$ \\
\hline \multirow{3}{*}{$\begin{array}{l}\text { Philippines } \\
\text { (PSEI) }\end{array}$} & Pre & 0.000076 & 0.00004 & 0.00324 & 0 & 0.00014 & 10.87 & 200.39 & $-30.50 *$ \\
\hline & Post & 0.00006 & 0.00003 & 0.00115 & 0 & 0.0001 & 6.09 & 53.79 & $-9.61 *$ \\
\hline & Combined & 0.00007 & 0.00004 & 0.00324 & 0 & 0.00013 & 9.44 & 171.1 & $-40.07^{*}$ \\
\hline \multirow{3}{*}{$\begin{array}{l}\text { China } \\
\text { (SSE) }\end{array}$} & Pre & 0.000179 & 0.00009 & 0.00373 & 0.000002 & 0.00029 & 5.04 & 41.2 & $-8.45^{*}$ \\
\hline & Post & 0.000159 & 0.00007 & 0.00409 & 0.000005 & 0.00034 & 6.46 & 58.47 & $-6.80 *$ \\
\hline & Combined & 0.00018 & 0.00008 & 0.00409 & 0.000002 & 0.00033 & 5.41 & 44.41 & $-6.32 *$ \\
\hline \multirow{3}{*}{$\begin{array}{l}\text { Singapore } \\
\text { (STI) }\end{array}$} & Pre & 0.000075 & 0.00004 & 0.00105 & 0 & 0.0001 & 3.73 & 24.38 & $-9.87 *$ \\
\hline & Post & 0.000042 & 0.00002 & 0.00092 & 0 & 0.00006 & 5.73 & 53.88 & $-7.05^{*}$ \\
\hline & Combined & 0.00008 & 0.00004 & 0.00545 & 0 & 0.00018 & 14.06 & 347.57 & $-8.20 *$ \\
\hline \multirow{3}{*}{$\begin{array}{l}\text { Taiwan } \\
\text { (TWII) }\end{array}$} & Pre & 0.000127 & 0.00007 & 0.00326 & 0.000003 & 0.00018 & 6.16 & 75.7 & $-8.98 *$ \\
\hline & Post & 0.000046 & 0.00003 & 0.00173 & 0.000003 & 0.00008 & 10.36 & 169.56 & $-17.39 *$ \\
\hline & Combined & 0.0001 & 0.00005 & 0.00326 & 0.000003 & 0.00016 & 6.59 & 83.12 & $-8.77^{*}$ \\
\hline
\end{tabular}

* denotes rejection of the null hypothesis of the unit root at the $1 \%$ significance level. Pre denotes the period before the subprime crisis (01 April 2000 to 15 September 2007) and the descriptive statistics for the pre GFC period are presented in the same row. Post denotes the post subprime crisis period (16 September 2007 to 03 April 2029). Combined denotes the full period of study (01 April 2000 to 03 April 2019). Statistics in the same row are for the corresponding periods. 
Table 1.2: Descriptive Statistics: Daily Returns

\begin{tabular}{l|cccccccc}
\hline Market & Mean & Median & Maximum & Minimum & Std. Dev. & Skewness & Kurtosis & ADF \\
\hline Australia (AORD) & 0.00022 & 0.00030 & 0.084832 & -0.09230 & 0.01026 & -0.39872 & 12.8921 & $-47.00^{*}$ \\
USA (DJI) & 0.000221 & 0.00040 & 0.058272 & -0.07870 & 0.01087 & -0.57986 & 9.6618 & $-49.00^{*}$ \\
Eurozone (EURO) & -0.00012 & 0.00051 & 0.089338 & -0.11392 & 0.01568 & -0.3955 & 8.56014 & $-37.04^{*}$ \\
UK (FTSE100) & $4.17 \mathrm{E}-05$ & 0.00033 & 0.101734 & -0.07325 & 0.01216 & 0.019852 & 10.3116 & $-36.67^{*}$ \\
Hong Kong (HSI) & 0.00012 & 0.00059 & 0.146832 & -0.14509 & 0.01680 & -0.34002 & 13.7730 & $-50.75^{*}$ \\
Indonesia (JKSE) & 0.00080 & 0.00163 & 0.187637 & -0.17673 & 0.01672 & -0.80965 & 22.8371 & $-38.40^{*}$ \\
Malaysia (KLSE) & 0.00021 & 0.00046 & 0.073822 & -0.11653 & 0.00988 & -1.09353 & 19.7170 & $-44.63^{*}$ \\
South Korea (KOSPI) & 0.00034 & 0.00064 & 0.126791 & -0.14382 & 0.01721 & -0.4522 & 11.6533 & $-26.27^{*}$ \\
India (NIFTY) & 0.00063 & 0.00111 & 0.125554 & -0.20883 & 0.01711 & -1.19052 & 19.0043 & $-47.04^{*}$ \\
Japan (NIKKEI) & $-1.19 \mathrm{E}-05$ & 0.00039 & 0.111885 & -0.12477 & 0.01624 & -0.6016 & 10.7191 & $-46.50^{*}$ \\
Philippines (PSEI) & 0.00053 & 0.00078 & 0.143117 & -0.16296 & 0.01518 & -0.06242 & 19.6259 & $-38.08^{*}$ \\
China (SSE) & 0.00018 & 0.00043 & 0.102257 & -0.12435 & 0.01761 & -0.33295 & 8.84843 & $-46.04^{*}$ \\
Singapore (STI) & 0.00015 & 0.00041 & 0.198372 & -0.16108 & 0.01369 & 0.223601 & 32.5781 & $-48.46^{*}$ \\
Taiwan (TWII) & $-5.10 \mathrm{E}-05$ & 0.00035 & 0.140371 & -0.13497 & 0.01598 & -0.65815 & 12.3305 & $-46.95^{*}$ \\
\hline
\end{tabular}

* denotes rejection of the null hypothesis of the unit root at the $1 \%$ significance level.

The ijth entry in Table 2 is the estimated contribution to the forecast error variance of market $i$ from innovations to market $j$. The off-diagonal column sums (labelled contributions to others) and row sums (labeled contributions from others) are the directional spillover to and from, respectively, and we can calculate the net volatility spillover as the difference between them. Additionally, the total volatility spillover index appears in the bottom right corner of the table. It is approximately the grand offdiagonal column sum (or row sum) relative to the grand column sum, including diagonals (or the row sum including diagonals), expressed as a percentage. In the volatility spillover table, the quantified ripple effects of the volatility shock in each country should be viewed as the input-output decomposition of the total volatility spillover index. Koutmos and Booth (1995) observed that national markets have grown more interdependent since the October 1987 crash, with a clear pattern emerging here as well: spillover both to and from others has increased considerably since the Lehman Brother collapse, whereas, in the case of Japan, the spillover is almost similar to that before the crisis. The to and from total spillover index values for the United States (DJI), the United Kingdom (FTSE), and the eurozone are higher than those of the other countries. Total spillover within the system consisting of the selected stock markets rose from $42.2 \%$ to $56.7 \%$ after the crisis, which is indicative of the higher level of integration among the stock markets.

The findings reveal that all the markets, except for Japan, are less susceptible to significant domestic volatility shocks in the pre-crisis period. The individual market analysis suggests that Japan and China differ from the other Asia-Pacific markets, as well as from the United States and the eurozone. China appears to be almost impregnable during the pre-crisis period, with $89.5 \%$ variation from its shocks and only $10.5 \%$ variation due to spillover from others, while the spillover from China to others has an index value of only 6.7. These values change significantly in the post-crisis world, where volatility spillover to China from others rises to $36.1 \%$, and spillover from China to others increases to an index value of 37.6. During the entire period of study, the total spillover index value for China remained the same, at 14, for spillover both to and from others. For Japan, spillover from others is around $49 \%$ of its variation during both the pre- and post-crisis periods, suggesting the crisis had a minimal impact on Japan's stock market. In terms of spillover from Japan to others, the spillover index value is stable at 33.2 (pre-crisis) and 30.6 (post-crisis), indicating that Japan's contribution to global spillover did not change due to the crisis. Net directional volatility spillover before the crisis is highest from the US and eurozone stock markets to the others, and from the others to Australia. However, after the crisis, net directional volatility spillover is again highest from the US stock markets to the others, and from the others to the stock markets of the Philippines and Australia. Overall, net directional volatility spillover is greatest from the US stock market to the others, and from the others to Australia. Japan and Australia show consistent behavior regarding net volatility spillover during both the pre- and postcrisis periods. 
Table 2: Directional spillover table

\begin{tabular}{|c|c|c|c|c|c|c|c|c|c|c|c|c|c|c|c|c|}
\hline & & DJI & FTSE & AORD & HIS & TWII & JIKKEI & STI & SSE & IFTY & JKSE & KOSPI & KLSE & PSEI & EURO & $\begin{array}{r}\text { From } \\
\text { Others }\end{array}$ \\
\hline \multirow{3}{*}{ DJI } & Pre & 45.9 & 16.39 & 2.44 & 1.99 & 3.7 & 2.16 & 2.68 & 0.2 & 0.1 & 0.89 & 3.27 & 0.98 & 0.14 & 19.17 & 54.1 \\
\hline & Post & 35.07 & 14.08 & 4.21 & 3.51 & 4.61 & 2.4 & 6.03 & 3.03 & 3.3 & 2.35 & 7.87 & 1.69 & 0.18 & 11.68 & 64.9 \\
\hline & ombined & 40.66 & 15.27 & 2.92 & 2.91 & 4.83 & 2.51 & 4.73 & 0.7 & 0.98 & 1.62 & 6.39 & 1.53 & 0.17 & 14.79 & 59.3 \\
\hline \multirow{3}{*}{ FTSE } & Pre & 16.44 & 38.9 & 3.75 & 2.4 & 3.16 & 2.63 & 3.79 & 0.03 & 0.12 & 0.75 & 1.75 & 1.07 & 0.21 & 24.99 & 61.1 \\
\hline & Post & 16.2 & 30.17 & 4.08 & 3.51 & 4.39 & 2.2 & 6.3 & 2.57 & 2.99 & 2.96 & 6.79 & 1.86 & 0.48 & 15.48 & 69.8 \\
\hline & Combined & 16.8 & 35.75 & 4.35 & 3.17 & 3.67 & 2.34 & 5.09 & 0.64 & 0.75 & 1.59 & 3.36 & 1.07 & 0.28 & 21.12 & 64.2 \\
\hline \multirow{3}{*}{ AORD } & Pre & 10.18 & 11.52 & 58.87 & 2.82 & 0.85 & 1.44 & 4.74 & 1.8 & 0.69 & 1.44 & 0.3 & 1.01 & 0.4 & 3.93 & 41.1 \\
\hline & Post & 11.62 & 8.27 & 39.86 & 4.46 & 4.48 & 3.52 & 5.08 & 4.14 & 2.2 & 1.98 & 6.19 & 1.97 & 0.75 & 5.48 & 60.1 \\
\hline & Comk & 10.76 & 11.63 & 53.97 & 4.08 & 0.95 & 1.67 & 4.74 & 2.91 & 0.59 & 1.4 & 0.44 & 0.35 & 0.43 & 6.11 & 46 \\
\hline \multirow{3}{*}{ HIS } & Pre & 3.97 & 5.85 & 1.38 & 50.66 & 5.74 & 3.57 & 9.49 & 0.21 & 2 & 2.2 & 6.19 & 6.07 & 0.26 & 2.41 & 49.3 \\
\hline & & 6.27 & 4.94 & 3.14 & 36.41 & 6.91 & 2.91 & 9.15 & 7.1 & 4.54 & 3.66 & 7.84 & 3.24 & 1.07 & 2.81 & 63.6 \\
\hline & Combined & 5.58 & 5.96 & 2.49 & 44.61 & 6.17 & 3.33 & 9.6 & 2.43 & 2.93 & 2.9 & 6.41 & 4.05 & 0.56 & 3 & 55.4 \\
\hline \multirow{3}{*}{ TWII } & & 5.35 & 4.82 & 0.2 & 5.86 & 52.6 & 3.89 & 3.58 & 0.43 & 0.29 & 0.8 & 11.92 & 3.78 & 0.04 & 46 & 7.4 \\
\hline & & 6.66 & 4.74 & 2.91 & 6.41 & 41.4 & 2.2 & 8.94 & 2.79 & 3.6 & 3.42 & 0.15 & 3.03 & 0.46 & 3.31 & 58.6 \\
\hline & Combined & 6.31 & 3.9 & 0.23 & 5.21 & 46.7 & 3.35 & 5.89 & 0.28 & 2.35 & 1.79 & 15.26 & 4.82 & 0.16 & 3.73 & 53.3 \\
\hline \multirow{3}{*}{ NIKKEI } & Pre & 5.32 & 6.58 & 1.29 & 5.37 & 4.27 & 50.66 & 6.1 & 0.49 & 1.29 & 1.55 & 6.2 & 2.9 & 0.08 & 1.9 & 9.3 \\
\hline & & 8.51 & 5.14 & 5.16 & 3.71 & 3.81 & 51.12 & 4.01 & 2.46 & 2.31 & 2.27 & 6.31 & 1.45 & 1.2 & 2.53 & 48.9 \\
\hline & Combined & 7.17 & 5.61 & 1.87 & 4.38 & 4.98 & 51.52 & 4.95 & 0.19 & 1.89 & 1.88 & 7.79 & 2.75 & 0.54 & 4.48 & 48.5 \\
\hline \multirow{3}{*}{ STI } & Pre & 6.88 & 8.95 & 2.32 & 9.53 & 3.82 & 4.35 & 41.3 & 0.37 & 1.71 & 2.02 & 4.56 & 7.2 & 0.63 & & 58.7 \\
\hline & & 10.07 & 8.24 & 2.62 & 6.92 & 7.7 & 2.47 & 30.6 & 2.21 & 4.83 & 6.65 & 7.94 & 3.54 & 1.21 & & 39.4 \\
\hline & Combined & 9.24 & 8.54 & 2.1 & 7.93 & 6.19 & 3.29 & 35.3 & 1.26 & 3.46 & 4.34 & 6.8 & 5.26 & 0.92 & & 84.7 \\
\hline \multirow{3}{*}{ SSE } & Pre & 0.08 & 0.04 & 2.74 & 0.63 & 0.3 & 0.76 & 0.54 & 89.46 & 0.27 & 0.46 & 2.28 & & 0.82 & & 10.5 \\
\hline & P & 3.75 & 2.7 & 2.38 & 9.9 & 3.0 & 1.1 & 2.18 & 63.89 & 1.54 & 1.83 & 3.18 & 2.51 & 0.18 & & 6.1 \\
\hline & bined & 1.3 & 0.72 & 2.6 & 3.97 & 0.42 & 0.17 & 1.52 & 85.59 & 1.27 & 1.17 & 0.24 & 0.44 & 0.54 & 0.04 & 14.4 \\
\hline \multirow{3}{*}{ NIFTY } & Pre & 2.41 & 1.82 & 1.95 & 6.66 & 0.68 & 2.53 & 5.07 & 0.43 & 70.27 & 2.44 & 1.21 & 3.57 & 0.33 & 0.61 & 29.7 \\
\hline & & 8.84 & 5.29 & 2.13 & 4.58 & 5.0 & 1.99 & 6.46 & 1.96 & 41.8 & 6.84 & 7.48 & 2.24 & 1.2 & & 8.2 \\
\hline & Combined & 5.54 & 2.62 & 0.9 & 4.69 & 3.7 & 2.41 & 6.1 & 1.52 & 54.88 & 4.65 & 6.55 & 4.35 & 0.78 & 1.2 & 45.1 \\
\hline \multirow{3}{*}{ JKSE } & Pre & 2.81 & 2.69 & 1.42 & 5.14 & 1.76 & 2.23 & 4.23 & 0.7 & 2.69 & 64.71 & 3.62 & 4.87 & 1.1 & 2.04 & 35.3 \\
\hline & & 6.65 & 4.89 & 1.63 & 2.97 & 5.6 & & 7.8 & 1.27 & 8.17 & 46.8 & & & & & 3.2 \\
\hline & L & 5.23 & 3.79 & 1.1 & 3.88 & 3.8 & 1.76 & 6.53 & 1.04 & 5.64 & 54.31 & 5.46 & 4.03 & 1.46 & 1.89 & 45.7 \\
\hline \multirow{3}{*}{ KOSPI } & Pre & 4.95 & 3.5 & 0.19 & 6.77 & 9.69 & 4.72 & 5.73 & 0.29 & 0.43 & 1.69 & 54.15 & 3.8 & 0.12 & 3.98 & 45.8 \\
\hline & & 10.11 & 5.9 & 3.45 & 5.91 & 7. & 3.23 & 7.69 & & 5.16 & 4.09 & 37. & & & & 62.4 \\
\hline & hines & 7.72 & 3.33 & 0.1 & 4.93 & 11 & 41 & 6.4 & 0 & 3.56 & 2.68 & 47 & 5.18 & 0.35 & & 52.8 \\
\hline \multirow{3}{*}{ KLSE } & P & 2.41 & 3.17 & & 7.81 & & 1.58 & 6.93 & 0.13 & 1.79 & 2.64 & 2.88 & 64.3 & 0.78 & 1.74 & 35.7 \\
\hline & & 4.85 & 3.37 & 2.23 & 5.34 & 5.34 & 2.46 & 5.88 & 3.6 & 3.31 & 4.71 & 4.01 & 51.94 & 1.09 & 1. & 48.1 \\
\hline & $c$ & 3.61 & 2.27 & 0.32 & & & 27 & 6.17 & & & 3.27 & & & & & 43.1 \\
\hline \multirow{3}{*}{ PSEI } & & 1.16 & 1.19 & 0.99 & 0.59 & 0. & 0.18 & 2.02 & 1.42 & 0.51 & 1.6 & 0.22 & 2.15 & 85.92 & 1.05 & 14.1 \\
\hline & & 3.78 & 1.82 & 2.07 & 2.5 & 1.6 & 3.48 & 3.61 & 1.44 & 3.06 & 5.51 & 3.23 & 2.89 & 64.01 & 0.95 & 36 \\
\hline & & & & & 1.36 & & & 2.9 & & 1.63 & & & 2.81 & 75.92 & & 24.1 \\
\hline \multirow{3}{*}{ EURO } & & 17.84 & 3.94 & 1.11 & 1.12 & 3.7 & 3.15 & 2.7 & 0.22 & 0.17 & 0.72 & 2.38 & 0.73 & 0.08 & 41.99 & 58 \\
\hline & & 15.94 & 19.85 & 2.88 & 2.99 & 3.65 & 1.4 & 4.67 & 2.51 & 2.21 & 1.72 & 5.69 & 1.31 & 0.21 & 34.96 & 65 \\
\hline & C & 17.35 & 23.53 & 2.35 & 2.13 & 3.5 & & 3.55 & 0.16 & 0.35 & 1.02 & 2.92 & 0.55 & 0.1 & 40.31 & 59.7 \\
\hline \multirow{3}{*}{ TO Others } & & 79.8 & 5 & 20. & 56.7 & & & 57. & 6.7 & 12 & 19.2 & 46.8 & 38. & 5 & & 590.3 \\
\hline & & 113.3 & 89.2 & 38.9 & 62.7 & & & 77. & 37.6 & 47.2 & 48 & 82.8 & 30.9 & 10.4 & 61.2 & 794.4 \\
\hline & Combine & 99 & 88.7 & 22.5 & 54 & 56. & 31.6 & 68.3 & 14 & 29.2 & 31.6 & 70.1 & 37.2 & 7.2 & 66.2 & 676.4 \\
\hline & Pre & 125.7 & 129.4 & 79.5 & 107.4 & 94. & 83.9 & 99 & 96.2 & 82.3 & 83.9 & 100.9 & 102.8 & 90.9 & 123.8 & $42.20 \%$ \\
\hline & & 148.3 & 119.4 & 78.7 & 99.1 & 10 & 81.7 & 109 & 101.5 & 89 & 94.8 & 120.4 & 82.9 & 74.4 & 96.1 & $56.70 \%$ \\
\hline & (u & 139.7 & 124.5 & 76.5 & 98.7 & 10 & 83.1 & 104 & 99.5 & 84.1 & 85.9 & 117.3 & 94.1 & 83.1 & 106.5 & $48.30 \%$ \\
\hline & Pre & 25.7 & 29.4 & -20.4 & 7.4 & -5.7 & -16.1 & -1 & -3.8 & -17.7 & -16.1 & 1 & 2.8 & -9.1 & 23.8 & \\
\hline & st & 48.4 & 19.4 & -21.2 & -0.9 & 5. & -18 & 8.5 & 1.5 & -11 & -5.2 & 20.4 & -17.2 & -25.6 & -3.8 & \\
\hline 1110 & Combined & 39.7 & 24.5 & -23.5 & -1.4 & 3.5 & -16.9 & 3.6 & -0.4 & -15.9 & -14.1 & 17.3 & -5.9 & -16.9 & 6.5 & \\
\hline
\end{tabular}

Note: Along each row in each period, the figures denote values of directional spillover index. Each value represents directional spillover from the different stock markets (j) (column heads) to the stock market (i) (represented in each row). The last column shows spillover received by each stock market (row under consideration) from all other stock markets. The "To Others" row represents spillover to all other stock markets. The total spillover row is obtained by vertical(column) summation of values of the same period. The values in each cell for net spillover is obtained as the difference between spillover "To Others" and spillover "From Others". Pre and Post denote the period before and after the subprime crisis respectively while Combined denotes the full period under study.

The total spillover of the system consisting of all the markets rise steadily and peaked during AugustSeptember 2008, just around the credit crisis. The peak persisted, indicating rising global market integration. Financial integration indicates the cohesion and comovement of financial markets and their ability to operate in similar directions, providing a cross-country dimension for each market's participants. The steady rise in spillover that led to the crisis suggests that financial integration can create conditions for higher volatility, by facilitating an abrupt reversal of capital flows, contagion, and the cross-border transmission of financial shocks. This increase in spillover is particularly salient 
when the institutional framework is not strong enough to identify and prevent adverse shocks. Policymakers might need to empirically validate whether the benefits of higher integration outweigh the risk of financial apocalypse. Obstfeld (1998) and Schmukler (2004) observed that crises and contagion are closely associated with the presence of asymmetric information and imperfect contract enforcement. Spillover started falling sharply around November 2012; it reached its low point in June 2013, when the Federal Reserve Board announced it was preparing to wind down its stimulus policies (initiated after the financial crisis) and the HSBC flash purchasing managers' index showed Chinese manufacturing activity had reached a nine-month low. These global events influenced the global markets, while investors were repricing their assets. However, most market regulators instituted central supervision and a robust institutional framework in the post-crisis period, and the shocks from these events did not increase the spillover. The low risk transfer was possibly due to improved institutional supervision and the learning curve effect. The findings support the wake-up call hypothesis, with the intriguing possibility of government policy mitigating contagion.

\subsection{Network diagrams}

Figures 1 to 3 show the connectedness diagrams of total spillover before and after the subprime crisis and another combining both periods, respectively.

\section{Figure 1: Total directional connectedness to others (pre-subprime crisis period).}

\section{Figure 2: Total directional connectedness to others (Post- subprime crisis period)}

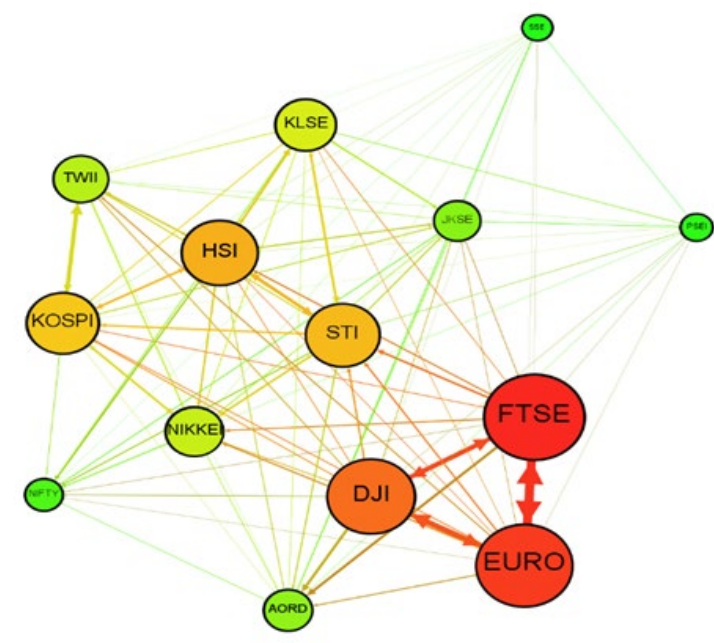

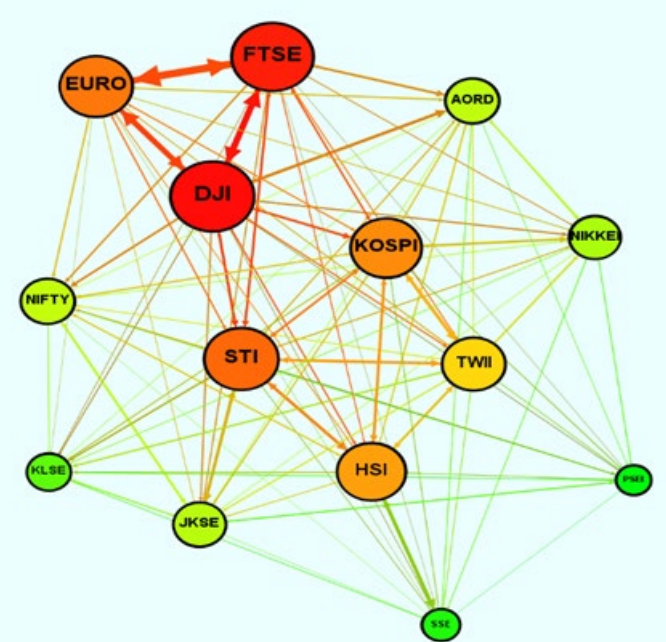

Note: We use this node color code to indicate total directional connectedness to others, from weakest to strongest. The color and size of the nodes indicate their relative contribution to the network (smaller size denotes smaller contribution). The color and strength of the arrows indicate the network's strength. Pre and Post denotes the period before and after the subprime crisis respectively while Combined denotes the full period under study. 


\section{Figure 3: Total directional connectedness (during the entire period of the study)}

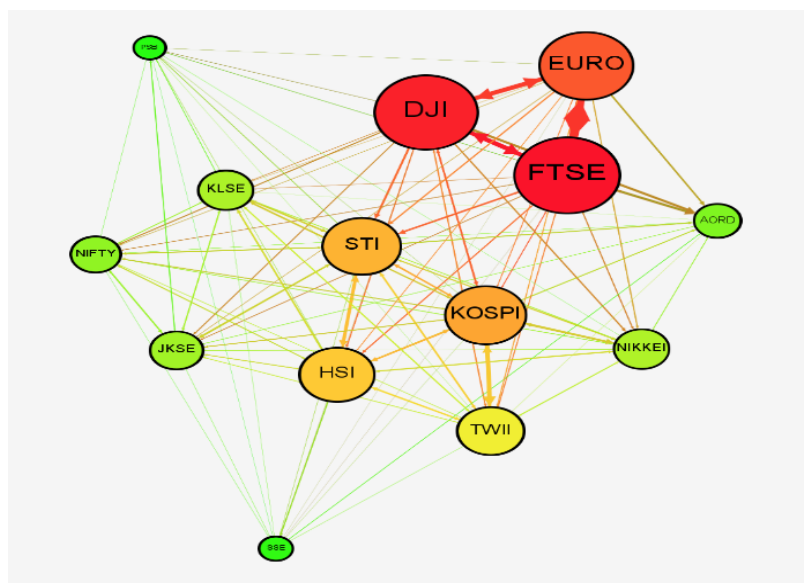

$$
\text { Low }
$$

Note: We use this node color code to indicate total directional connectedness to others, from weakest to strongest. The color and size of the nodes indicate their relative contribution to the network (smaller size denotes smaller contribution). The color and strength of the arrows indicate the network's strength. Pre and Post denotes the period before and after the subprime crisis respectively while Combined denotes the full period under study.

In Figures 1 and 2, the connectedness between the chosen stock markets becomes stronger (more reddish circles) after the collapse of Lehman Brothers led the financial crisis around the world. Spillover from Hong Kong to China increases during the post-crisis period. The influence of the eurozone is reduced, and that of the United States has increased. However, China still differs in this context, since the SSE is still not highly networked, while other markets in the region are. The network diagrams revealing directional spillover show that China (SSE) stands separate, with the fewest connections. Congruent with the findings of Rejeb and Boughrara (2015), the diagrams suggest that geographical proximity is closely associated with connectedness. Total connectedness during the entire period (Figure 3) shows the connectedness between the Asia-Pacific stock markets and the US and eurozone markets, with China being the least connected to others.

The spillover from the system in Figure 4 clearly shows that the top five markets (i.e., the United Kingdom, Singapore, the Eurozone, the United States, and Hong Kong) that received spillover from others did not change between the pre- and post-crisis periods, even if we consider the entire period, although their relative positions change within the top five. Spillover to China and the Philippines from others was lowest during both the pre- and post-crisis periods, although the Chinese stock market (SSE) is much larger and more developed compared to that of the Philippines.

\section{Figure 4: Spillover from the system}

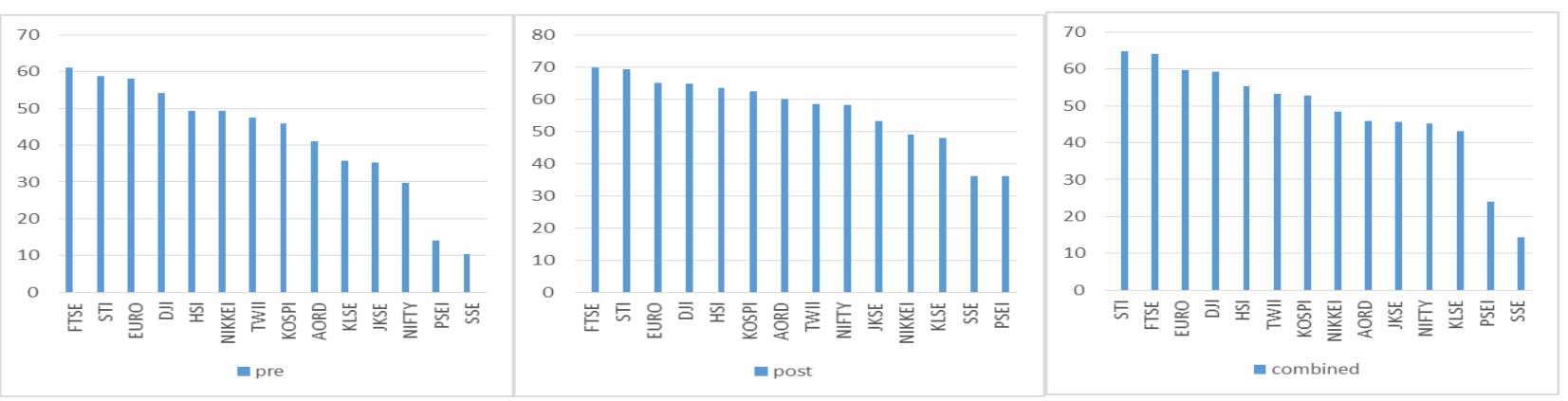

Note: This is a graphic representation of the data available in the last column of table 2 visualizing directional spillover from the system. The figure shows consecutively the equity market that receives the highest to lowest (left to right) spillover from others. Pre and Post denotes the period before and after the subprime crisis respectively while Combined denotes the full period under study. 
These findings are in line with the observations of Zhou et al. (2012), Allen et al. (2013), and Jebran et al. (2017), where the impact of the global financial crisis on the Chinese stock market was minimal and did not affect its connectedness with others in the region. China was and continues to be less connected to other stock markets, presumably because of the restrictions on foreign capital flow into its stock market. Our results contradict the findings of Jebran et al. (2017), in the sense that we provide evidence of stronger bidirectional connectedness between the Chinese and Hong Kong stock markets after the crisis, whereas they argued for volatility spillover from Hong Kong to China.

\subsection{Time Variation in Volatility Spillover}

Figure 5 shows the time-varying spillover index plot, obtained using "to others" directional spillover index values, estimated using 150 days rolling window.

\section{Figure 5: Time-varying Spillover Plot}

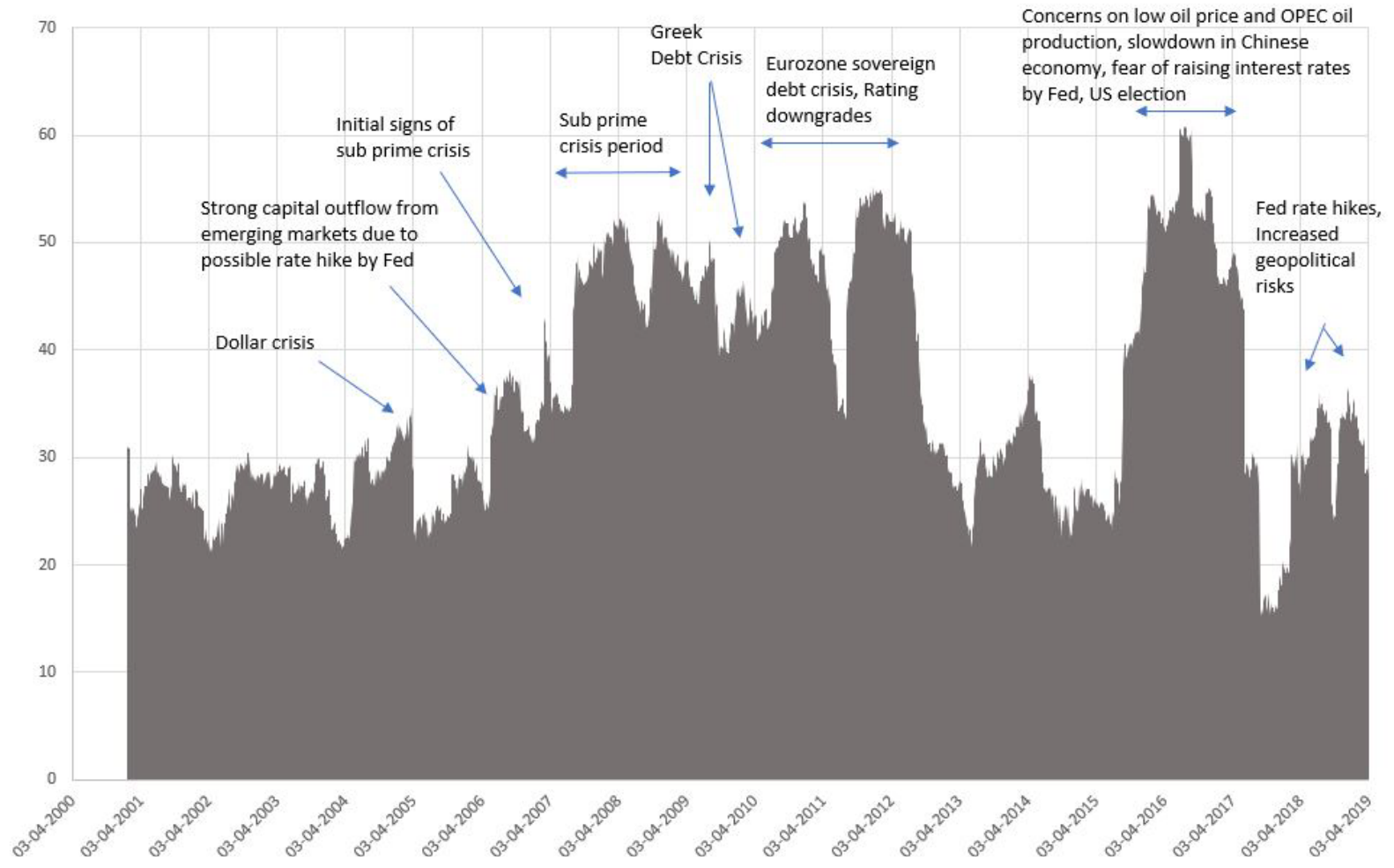

Note: The figure represents spillover index measuring contribution to other markets, obtained as a summation of variance decomposition of spillover contribution to others, estimated over a rolling period of 150 days.

Figure 5 clearly shows the time-varying nature of volatility spillover and its peaks during crisis events. The figure also shows that the peaks are higher during the European debt crisis (EDC) than they were during the US subprime crisis or even before the US subprime crisis. The result is not surprising given that the European Union, along with the US, are the main markets for the Asia-Pacific economies and the majority of these economies depend heavily on these exports. While the US market was still recovering from the impact of the subprime crisis, the EDC led the Asia-Pacific markets to experience macroeconomic shocks owing to trade ties with crisis-hit countries. However, bursts during EDC in figure 5 also shows the presence of financial linkage between Asia-Pacific and EDC hit countries at least through equity markets.

The bursts in volatility spillover between Asia-Pacific markets have been observed during the following events: 
1) Dollar crisis during March 2005 when policymakers of various Asia-Pacific nations like China, Japan, India and Korea showed intension of diversifying forex reserve.

2) The significant outflow of funds from emerging markets due to the Federal Reserve's rate hike signals in 2006.

3) Subprime crisis in the US in 2007 and 2008 that led to the collapse of Lehman Brothers, followed by a global financial crisis.

4) The Greek debt crisis and downgrading of Greek bank and government debt in 2009.

5) Eurozone sovereign debt crisis during 2010-2012.

6) Uncertainties and economic events in 2016 and 2017, such as low crude oil prices, indications of a downturn in the Chinese economy, expectations for a Fed rate hike, US election results and the confusion surrounding the US relationship with Russia, China and North Korea.

7) Concerns due to increased geopolitical risks caused by the US-China trade war beginning with imposing tariffs on each other's products, multiple rate hikes by Federal Reserve and uncertainties over Britain leaving the European Union.

As displayed in figure 5, there are three periods where we observe spillover bursts. We build the connectedness diagrams (figure 6,7 and 8) for the three periods:

- Subprime crisis period (February 2007 to December 2009): The starting date coincides with the announcement made by Freddie Mac that it will no longer buy the riskiest subprime mortgages and mortgage-related securities. The period considered is till Dec 2009 when the US Treasury Department announces the removal of caps on the amount of preferred stock that the Treasury may purchase in Fannie Mae and Freddie Mac, besides Federal Reserve Bank declaring that it would offer interest-bearing term deposits to eligible institutions through an auction mechanism. The figure 6 shows that the US market is the most influential contributor to volatility spillover during the period compared to the other markets. The observation is not surprising as the US is the origination point of the subprime crisis.

- European Debt Crisis period (December 2009 to Nov 2012): Fitch, S\&P, Moody's downgraded Greece credit rating in December 2009 and that is the initial signal of the crisis in Europe. The period considered is till November 2012, when Eurozone nations and the IMF agreed to a revised aid deal for Greece, including lower interest rates on bailout loans and a debt-buyback. We find that the spillover (to others) initially reduces and then increases. Finta et al. (2019) observes similar spillover effect (decrease followed by increase) during EDC between the German stock market and the Greek, Italian, Portuguese and Spanish stock markets. During the period (figure 7), we find that the Australian stock market is the largest volatility spillover contributor to others, and the UK market follows next. While the UK is a European nation and as a member of the EU, is expected to witness the ripple effects of the EDC, the emergence of Australia as a leading contributor of volatility across the markets (as indicated by the red colored arrows) is expected to give newer insights in further studies.

- Increased geopolitical risks and uncertainty (December 2015 - July 2017): The period witnessed many events that arguably led to the increase in spillover between Asia-pacific markets. U.S. Federal Reserve raised interest rates in Dec 2015 for the first time since before the global financial crisis. Throughout the period, the markets witnessed uncertainty and increased geopolitical risks from falling crude prices; slowdown and debt pile in China; US election and post-election uncertainties in the domestic US market and its external relationships with China, Russia and North Korea; and apprehensions about a further rate hike by US Federal Reserve that can alter the course of international capital flows. Australian stock market remained the leading contributor to the volatility spillover to the network during the time. The spillover between the Japanese, Singaporean, Malaysian and Indian stock markets is observed at a medium level. During this 
time, though, the US market is comparatively less connected. China and Hong Kong markets are least connected as shown by their network strength.

During all three periods, the Chinese equity market remains least connected with the other markets. The observation is in line with the earlier findings.

Connectedness during bursts in Spillover:

Figure 6: Subprime Crisis

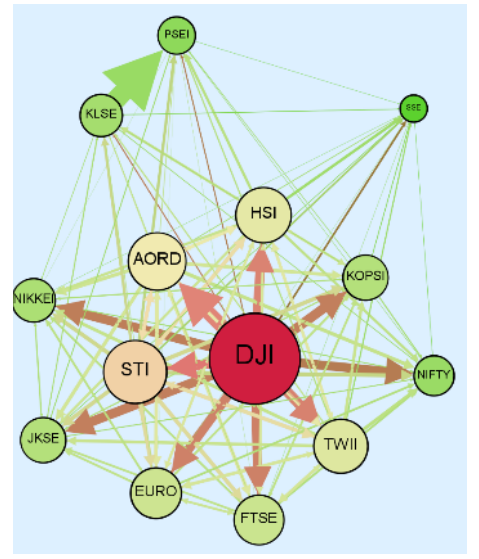

Figure 7: European Debt Crisis

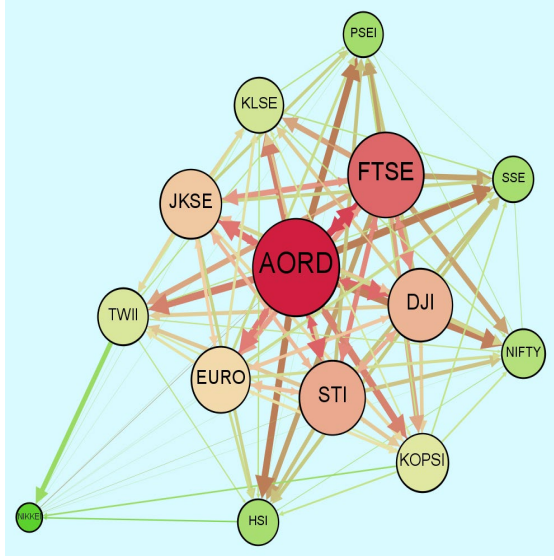

Figure 8: Geopolitical Uncertainty

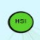

D

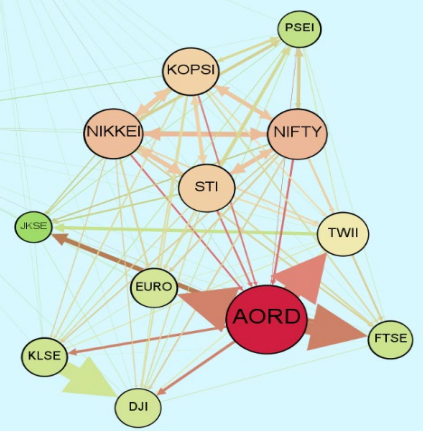

Low

High

We use this node color code to indicate total directional connectedness to others, from weakest to strongest. The color and size of the nodes indicate their relative contribution to the network (smaller size denotes smaller contribution, spillover increases as color changes from green to red).

During the three spillover burst periods, the relative contribution to the network varies across different markets. During the subprime crisis, the contribution of the US market was relatively much higher compared to any other market. During the European Debt Crisis, the Australian market emerged as the leading volatility spillover contributor to others, followed by the UK market. The emergence of the Australian market as a contributor to volatility spillover to other markets continued even after the EDC when the world markets witnesses increased uncertainty due to geopolitical situations. China remained least connected during all the periods.

\section{Conclusion}

The rationale behind international diversification is based on the expectation that most economic disturbances to be country specific, resulting in relatively low correlations between stock markets. If markets are connected, this would undermine much of the rationale for international diversification, because ignoring the connectedness can lead to poor portfolio diversification and an underestimation of risk. Except China, the US, UK, EU and the Asia-Pacific markets are reasonably connected between themselves, although the strength of their network varies over the period. The Chinese stock market had kept itself relatively insulated, even though it remained a volatile market throughout the study period. Of all the Asia-Pacific markets, those of South Korea (KOSPI), Hong Kong (HSI), and Singapore (STI) make the largest contribution to risk transfer. Market size does not determine the level of connectedness either, since it is clear that three big stock markets (in terms of volume), namely, Japan, China, and Australia, are less connected compared to the most connected countries. Geographical proximity seems to be a factor in increasing volatility spillover. These findings have significance for multinational portfolio management. Overall, while all the other stock markets are connected in terms of risk transfer (volatility spillover), the Chinese stock market experienced least 
volatility spillover from other markets. China's stringent financial market rules combined with the restrictions on non-Chinese participation in its stock markets could be the reason for the Chinese stock market's relative insulation.

The time variations in spillover show peaks and troughs, which may be aligned with readily recognizable international events. We also found overall network strength gradually increased, leading to the global financial crisis, symptomatic of the evolution of the subprime crisis into a global financial crisis. Interestingly, network strength seems to have increased since the crisis and has remained above its pre-crisis level. The transmission of volatility was higher during EDC and even after EDC than it was during the time of subprime crisis. This finding could be a sign of the integration of global standards of market regulation and the increased confidence level of transnational investment agents. However, it also indicates that shock to any one of these markets has the potential to spread to others very quickly and develop into a multi-country phenomenon. The network's strength always drastically fell after a stock market crash, indicating the disintegration of markets after a crash, which could be due to the withdrawal of investment from foreign markets. It is therefore possible that, whenever a major crash occurs, global investment firms will curtail their transnational activities, providing a window of opportunity for contrarians.

In the case of a new global crisis, some of these markets, such as South Korea, Hong Kong, and Singapore, are likely to be as badly hit as the Western markets. Future research could focus on dynamic hedging possibilities using an Asia-Pacific portfolio. On the policy front, the findings call for stronger supervision and regulations to mitigate the rising risks from market connectedness. Between highly connected markets, an adverse shock to one market has the potential to negatively impact the international fund flows to other markets, even if the other markets have strong fundamentals. This could trigger a financial crisis in other markets, one that is utterly unwarranted by those countries' fundamentals and policies. Stronger regulations should help in reducing the impact and in obtaining dedicated funds to stabilize the system. Financial market policies should encourage and improve the resilience of financial markets against shocks. However, this in itself requires more granular and timely information from market participants, and regulations on the capture of such data could help improve the flow of information and market monitoring.

\section{References}

Abidin, S., Reddy, K. \& Zhang, C. (2014). Intensity of Price and Volatility Spillover Effects in Asia-Pacific Basin Equity Markets, Australasian Accounting, Business and Finance Journal, 8(5), 3-18.

Acharya, V., Pedersen, L. H., Philippon, T., \& Richardson, M. P. (2010). Measuring systemic risk. AFA 2011 Denver Meetings Paper, Denver, CO. (http://dx.doi.org/10.2139/ssrn.1573171).

Adrian, T., \& Brunnermeier, M. K. (2011). CoVaR. NBER working paper no. 17454.

Ahmed, A. D. \& Huo, R. (2019). Impacts of China's crash on Asia-Pacific financial integration: Volatility interdependence, information transmission and market comovement, Economic Modelling, 79(C), 28-46

Allen, D.E, Amram, R., \& McAleer, M. (2013). Volatility spillovers from the Chinese stock market to economic neighbours. Mathematics and Computers in Simulation, 94, 238-257.

Allen, D.E., McAleer, M., Powell, M.J. \& Singh, A. (2017). Volatility Spillovers from Australia's major trading partners across the GFC, International Review of Economics and Finance, 47, 159-175. 
Alaganar, V. T. and Bhar, R. (2002). Information and volatility linkage under external shocks: Evidence from dually listed Australian stocks, International Review of Financial Analysis, 11, 59-71.

Alper, E., \& Yilmaz, K. (2004). Volatility and contagion: Evidence from the Istanbul Stock Exchange. Economic Systems, 28(4), 353-367.

Aloui, R., Ben, M.S., \& Nguyen, D.K. (2011). Global financial crisis, extreme interdependences, and contagion effects: the role of economic structure? Journal of Banking and Finance, 35, 130-141.

Anastasopoulos, A. (2018). Testing for financial contagion: New evidence from the Greek crisis and yuan devaluation. Research in International Business and Finance, 45, 499-511.

Baruník, J., Kočenda, E., \& Vacha, L. (2016). Asymmetric connectedness on the U.S. stock market: Bad and good volatility spillovers. Journal of Financial Markets, $27(C), 55-78$.

Bauwens, L., Hafner, C., \& Pierret, D. (2013). Multivariate volatility modeling of electricity futures. Journal of Applied Econometrics, 28(5), 743-761.

Bauwens, L., Laurent, S., \& Rombouts, J. (2006). Multivariate GARCH models: A survey. Journal of Applied Econometrics, 21 (1), 79-109.

BenSaïda, A., Litimi, H., \& Abdallah, O. (2018). Volatility spillover shifts in global financial markets. Economic Modelling, 73, 343-353.

Bhattacharjee, B., Shafi, M., \& Acharjee, A. (2019). Network mining-based elucidation of the dynamics of cross-market clustering and connectedness in Asian region: An MST and hierarchical clustering approach. Journal of King Saud University - Computer and Information Sciences, 31 (2), 218-228.

Billio, M., \& Pelizzon, L. (2003). Contagion and interdependence in stock markets: Have they been misdiagnosed? Journal of Economics and Business, 55(5-6), 405-42.

Bissoondoyal-Bheenick, E., Brooks, R. Chi, W and Do, H.X. (2018). Volatility spillover between the US, Chinese and Australian stock markets, Australian Journal of Management, 43(2), 263-285.

Caloia, F. G., Cipollini, A., \& Muzzioli, S. (2018). Asymmetric semi-volatility spillover effects in EMU stock markets. International Review of Financial Analysis, 57, 221-230.

Cappiello, L., Engle, R. F., \& Shephard, K. (2006). Asymmetric dynamics in the correlations of global equity and bond returns. Journal of Financial Econometrics, 4(4), 537-572.

Cheng, H. \& Glascock, J.L. (2006). Stock Market Linkages Before and After the Asian Financial Crisis: Evidence from Three Greater China Economic Area Stock Markets and the US, Review of Pacific Basin Financial Markets and Policies, 9(2), 297-315

Conrad, C., \& Karanasos, M. (2010). Negative volatility spillovers in the unrestricted ECCC-GARCH model. Econometric Theory, 26 (3), 838-862.

Demirer, M., Diebold, F. X., Liu, L., \& Yilmaz, K. (2017). Estimating global bank network connectedness. Journal of Applied Economics, 33, 1-15.

Diebold, F., \& Yilmaz, K. (2009). Measuring financial asset return and volatility spillovers, with application to global equity markets. The Economic Journal, 119, 158-171.

Diebold, F., \& Yilmaz, K. (2011). Equity market spillovers in the Americas. In R. Alfaro (ed.), Financial Stability, Monetary Policy, and Central Banking. Santiago: Bank of Chile Central Banking Series, 15 , 199-214. 
Diebold, F., \& Yilmaz, K. (2012). Better to give than to receive: Predictive directional measurement of volatility spillovers. International Journal of Forecasting, 28, 57-66.

Diebold, F., \& Yilmaz, K. (2014). On the network topology of variance decompositions: Measuring the connectedness of financial firms. Journal of Econometrics, 182, 119-134.

Diebold, F., \& Yilmaz, K. (2016). Trans-Atlantic equity volatility connectedness: U.S. and European financial institutions, 2004-2014. Journal of Financial Econometrics, 14(1), 81-127.

Dungey, M., \& Gajurel, D. (2014). Equity market contagion during the global financial crisis: Evidence from the world's eight largest economies. Economic Systems, 38(2), 161-177.

Engle, R., \& Kelly, B. (2012). Dynamic equicorrelation. Journal of Business \& Economic Statistics, 30 (2), 212-228.

Engle, R. F., \& Kroner, K. (1995). Multivariate simultaneous generalized ARCH. Econometric Theory, $11,122-150$.

Engle, R., \& Susmel, R. (1993). Common volatility in international equity markets. Journal of Business and Economic Statistics, 11 (2), 167-176.

Engle, R. F., \& Takatoshi, I., \& Lin, W. (1990). Meteor showers or heat waves? Heteroskedastic intradaily volatility in the foreign exchange market. Econometrica, 58(3), 525-542.

Ferris, S. P., Jayaraman, N. \& Sabherwal, S. (2007). Characteristics and behavior of newly listed firms: Evidence from the Asia-Pacific region, Journal of International Financial Markets, Institutions and Money, 17(5), 420-436.

Finta, M. A., Frijns, B., \& Tourani-Rad, A. (2019). Time-varying contemporaneous spillovers during the European debt crisis. Empirical Economics, 57, 423- 448.

Forbes, K. J. (2012). The "Big C": Identifying and mitigating contagion. The Changing Policy Landscape. 2012 Jackson Hole Symposium, Jackson Hole, WY, 23-87.

Forbes, K. J., \& Rigobon, R. (2002). No contagion, only interdependence: Measuring stock market comovements. Journal of Finance, 57(5), 2223-2261.

Gallo, G., \& Otranto, E. (2008). Volatility spillovers, interdependence and comovements: A Markov switching approach. Computational Statistics and Data Analysis, 58, 301 1-3026.

Guimaraes-Filho, R \& Hong, G. H. (2016). Dynamic connectedness of Asian equity markets. IMF working paper, WP/16/57.

Hemche, O., Jawadi, F., Maliki, S. B., \& Cheffou, A. I. (2016). On the study of contagion in the context of the subprime crisis: A dynamic conditional correlation-multivariate GARCH approach. Economic Modelling, 52, 292-299.

Jebran, K., Chen, S., Ullah, I., \& Mirza, S. S. (2017). Does volatility spillover among stock markets varies from normal to turbulent periods? Evidence from emerging markets of Asia. The Journal of Finance and Data Science, 3(1-4), 20-30.

Johansson, A. \& Ljungwall, C. (2009). Spillover Effects Among the Greater China Stock Markets, World Development, 37(4), 839-851,

Johnson, R. \& Soenen, L. (2002). Asian Economic Integration and Stock Market Comovement. Journal of Financial Research, 25, 141-157. 
Kearney, C. (2000). The determination and international transmission of stock market volatility. Global Finance Journal, 11, 31-52.

Kolluri, B., Susan M. \& Wahab, M. (2014). Comovements of US and Asian Equity Markets: Evidence from Asymmetric and Time-Varying Coefficients, Review of Pacific Basin Financial Markets and Policies, 17(4), 1450021.

Koop, G., Pesaran, M., \& Potter, S. (1996). Impulse response analysis in Nonlinear multivariate models. Journal of Econometrics, 74, 119-147.

Koutmos, G., \& Booth, G. G. (1995). Asymmetric volatility transmission in international stock markets. Journal of International Money and Finance, 14(6), 747-762.

Kroner, K., \& Ng, V. (1998). Modeling asymmetric comovements of asset returns. The Review of Financial Studies, 11 (4), 817-844.

Li, Y., \& Giles, D. (2015). Modelling volatility spillover effects between developed stock markets and Asian emerging stock markets. International Journal of Finance and Economics, 20, 155-177.

Ling, S., \& McAleer, M. (2003). Asymptotic theory for a vector ARMA GARCH model. Econometric Theory, 19, 280-310.

Liu, Y. Angela \& Pan, M. (1997). Mean and Volatility Spillover Effects in the U.S. and Pacific-Basin Stock Markets, Multinational Finance Journal, 1 (1), 47-62

Longin, F., \& Solnik, B. (1995). Is the correlation in international equity returns constant: 1960-1990? Journal of international Money and Finance, 14, 3-23.

Markwat, T., Kole, E. \& Dijk, D. (2009). Contagion as a domino effect in global stock markets. Journal of Banking \& Finance, 33(11), 1996-2012.

Mitra, A. \& Iyer, V. (2016). Transmission of Volatility across Asia-Pacific Stock Markets:Is There a Pattern? IIM Kozhikode Society \& Management Review, 6(1) 42-54.

Nobi, A., Lee, S., Kim, D. H., \& Lee, J. W. (2014). Correlation and network topologies in global and local stock indices. Physics Letters A, 378(34), 2482-2489.

Nomikos, N., \& Salvador, E. (2014). The role of volatility regimes on volatility transmission patterns. Quantitative Finance, 14(1), 1-13.

Obstfeld, M. (1998). The global capital market: Benefactor or menace? Journal of Economic Perspectives, 12, 9-30.

Otranto, E. (2015). Capturing the spillover effect with multiplicative error models. Communications in Statistics - Theory and Methods, 44 (15), 3173-3191.

Pesaran, M., \& Shin, Y. (1998). Generalized impulse response analysis in linear multivariate models. Economics Letters, 58, 17-29.

Reinhart, Carmen and Calvo, Sara, (1996), Capital Flows to Latin America: Is There Evidence of Contagion Effects? p. 151-171 in Calvo, Guillermo A., Goldstein, Morris and Hochreiter, Eduard eds., Private Capital Flows to Emerging Markets After the Mexican Crisis, Peterson Institute for International Economics

Rejeb, A., \& Boughrara, A. (2015). Financial integration in emerging market economies: Effects on volatility transmission and contagion. Borsa Istanbul Review, 15(3), 161-179. 
Rigobon, R. (2016). Contagion, spillover and interdependence. European Central Bank working paper, no. 1975 (http://dx.doi.org/10.2866/81991)

Ross, S. (1989). Information and volatility: The no-arbitrage martingale approach to timing and resolution irrelevancy. The Journal of Finance, 44(1), 1-17.

Schmukler, S. L. (2004). Financial globalization: Gain and pain for developing countries. Economic Review, 89(2), 39-66.

Silvennoinen, A., \& Terasvirta, T. (2009). Modeling multivariate autoregressive conditional heteroskedasticity with the double smooth transition conditional correlation GARCH model. Journal of Financial Econometrics, 7(4), 373-411.

Soriano Felipe, P., \& Climent, F. (2006). Volatility transmission models: A survey. Revista de Economía Financiera, 10, 32-81.

Tsai, I-C. (2014). Spillover of fear: Evidence from the stock markets of five developed countries. International Review of Financial Analysis, 33, 281-288.

Wang, G.-J., Xie, C., \& Stanley, H. E. (2018). Correlation structure and evolution of world stock markets: Evidence from Pearson and partial correlation-based networks. Computational Economics, 51 (3), 607-635

Xu, Y., Taylor, N., \& Lu, W. (2018). Illiquidity and volatility spillover effects in equity markets during and after the global financial crisis: An MEM approach. International Review of Financial Analysis, 56, 208-220.

Yilmaz, K. (2010). Return and volatility spillovers among the East Asian equity. Journal of Asian Economics, 21, 304-313.

Zhao, L., Li, W., \& Cai, X. (2016). Structure and dynamics of stock market in times of crisis. Physics Letters A, 380(5-6), 654-666.

Zhou, X., Zhang, W., \& Zhang, J. (2012). Volatility spillovers between the Chinese and world equity markets. Pacific-Basin Finance Journal, 20(2), 247-270. 